Original Research Paper

\title{
Metabolite profiling of agarwood (Gyrinops versteegii (Gilg.) Domke) leaves from difference growth locations using Thin Layer Chromatography
}

\author{
Dwi Indriani Manurung ${ }^{1}$, Lisna Hidayati ${ }^{1}$, Nastiti Wijayanti ${ }^{1}$, Tri Rini Nuringtyas ${ }^{{ }^{*}}$ \\ ${ }^{1}$ Faculty of Biology, University of Gadjah Mada, Yogyakarta, Indonesia.
}

\author{
Article History \\ Received : June $06^{\text {th }}, 2021$ \\ Revised : July $04^{\text {th }}, 2021$ \\ Accepted : August $10^{\text {th }}, 2021$ \\ Published : August 18 ${ }^{\text {th }}, 2021$ \\ *Corresponding Author: \\ Tri Rini Nuringtyas, \\ Faculty of Biology, Universitas \\ of Gadjah Mada, Yogyakarta, \\ Indonesia; \\ Email: tririni@ugm.ac.id
}

\begin{abstract}
Gyrinops versteegii (Gilg) Domke is an agarwood-producing plant originating from Eastern Indonesia. Leaves have antioxidant and anticancer activity due to their secondary metabolites. However, secondary metabolites are strongly influenced by the environment. This study aims to compare the terpenoid, phenolic, and flavonoid profiles of agarwood leaves grown in three locations, namely Bogor, Mataram, and Sambas using Thin Layer Chromatography (TLC), in order to obtain the most potential agarwood $G$. versteegii for further development as herbal medicine. Agarwood leaf powder was extracted using Soxhlet with $80 \%$ methanol as solvent, followed by liquid-liquid fractionation using chloroform and aquadest. The crude extract and the obtained fraction were subjected to metabolite profiling using TLC. Racing data factors from TLC were analyzed using hierarchical cluster analysis (HCA). The results showed that the Mataram sample produced higher yields for both extracts and fractions. TLC detected that the chloroform fraction contained more terpenoids, followed by phenolics and flavonoids, while the aqueous fraction contained the same number of positive bands for terpenoids and phenolics. In terms of origin, the Bogor sample showed six terpenoid positive bands higher than the other samples. A similar pattern was observed in the phenolics, while the flavonoids were the same for all samples. HCA resulted in Mataram being clustered separately from the Bogor and Sambas samples. Agarwood leaves from Mataram cannot be used to replace agarwood leaves from Bogor and Sambas as herbal ingredients.
\end{abstract}

Keywords: Agarwood; Gyrinops versteegii; secondary metabolites; TLC; Phytochemical screening.

\section{Pendahuluan}

Tumbuhan obat / herbal telah digunakan untuk membantu pengobatan berbagai penyakit di banyak negara maju dan berkembang seperti di Cina kontribusi tumbuhan obat hampir mencapai $80 \%$ sedangkan di Amerika Serikat hampir mencapai $25 \%$ (Abdullahi et al., 2017). Indonesia merupakan negara dengan keanekaragaman hayati yang melimpah, serta memiliki tradisi penggunaan obat herbal dari zaman dahulu (Sumarni et al., 2019). Berdasarkan database LIPI (2015), Indonesia memiliki hampir 30 ribu hingga 50 ribu jenis tumbuhan, dan diantaranya sekitar \pm 7.500 tumbuhan digunakan sebagai tumbuhan obat.
Gaharu jenis Gyrinops versteegii (Gilg) Domke, merupakan tumbuhan asli Indonesia dan terdistribusi luas di wilayah timur Indonesia (Mulyaningsih et al., 2014). Tumbuhan ini berpotensi untuk dikembangkan sebagai obat herbal (Novriyanti et al., 2010) dan telah digunakan oleh masyarakat di berbagai daerah dalam bentuk teh herbal (Mulyaningsih et al., 2014; Susilo, 2014).

Gyrinops versteegii banyak diminati oleh masyarakat karena kemampuannya dalam memproduksi resin gaharu yang bernilai ekonomi tinggi. Resin gaharu merupakan hasil interaksi antara tanaman tersebut dengan jamur, $G$. versteegii biasanya dibudidayakan hingga umur 3-5 tahun untuk siap diinokulasi dengan 
jamur jenis Fusarium sp dan Rhizopus sp. (Wahyuni et al., 2020). Perkebunan G. versteegii dapat ditemukan di wilayah Sumatera, Jawa dan Kalimantan dengan kemelimpahan yang lebih rendah dibandingkan persebarannya di wilayah Timur sebagai habitat alaminya (Rindyastuti et al., 2019). Penelitian ilmiah tentang potensi Gyrinops versteegii sebagai herbal telah dilaporkan oleh Nuringtyas et al., (2018) yang menunjukkan daun $G$. versteegii memiliki aktivitas antioksidan dan anti proliferasi sel kanker serviks (HeLa) yang tinggi. Profil metabolit daun $G$. versteegii dianalisa dengan GC-MS menunjukkan bahwa ekstrak kloroformnya memiliki 15 metabolit yang berpotensi sebagai anti kanker (Wardana et al., 2019).

Tanaman herbal memiliki bioaktivitas yang mendukung kesehatan karena kandungan metabolit sekundernya. Produksi metabolit sekunder pada suatu tanaman baik secara kuantitatif dan kualitatif sangat bervariasi dan dipengaruhi oleh lingkungan (Ramakrishna \& Ravishankar, 2011). Indikasi variasi kandungan metabolit sekunder pada daun $G$. versteegii telah dilaporkan oleh Widayat et al., (2021) yang membandingkan daun G. versteegi dari Mataram dan Bogor. Daun dari Mataram memiliki profil terpenoid yang lebih beragam daripada daun asal Bogor. Berdasarkan alasan tersebut penelitian lanjutan ini dilakukan dengan penambahan lokasi di pulau Kalimantan (kota Sambas) dan pendekatan kromotografi yang berbeda. Penelitian ini bertujuan untuk mengevaluasi variasi profil metabolit daun G. versteegii yang tumbuh di tiga wilayah berbeda Bogor, Mataram dan Sambas yang diketahui memiliki parameter lingkungan yang berbeda.

\section{Bahan dan Metode}

\section{Bahan}

Daun gaharu yang digunakan dalam penelitian ini adalah daun dewasa berwarna hijau tua yang sehat dan tidak terindikasi terkena penyakit. Sampel dari kota Mataram diperoleh dari Balai Penelitian dan Pengembangan Teknologi Hasil Hutan Bukan Kayu (BPPTHHBK). Berdasarkan BPS tahun (2015), Kota Mataram secara geografis terletak pada koordinat $116^{\circ} 04^{\prime}-116^{\circ} 10^{\prime} \mathrm{BT}$, dan $08^{\circ} 33^{\prime}$ $08^{\circ} 38^{\prime}$ LS. Sedangkan, sampel dari Bogor dikoleksi dari Kebun Raya Bogor yang terletak pada koordinat $106^{\circ} 48^{\prime} \mathrm{BT}$ dan $6^{\circ} 26^{\prime} \mathrm{LS}$.

Sampel dari Sambas diambil dari perkebunan masyarakat di Sebubus, Kabupaten Sambas, Kalimantan Barat dengan titik koordinat $1^{\circ} 23^{\prime}$ " LU dan $108^{\circ} 39^{\prime \prime}$ BT. Daun yang dipetik terlebih dahulu dilayukan di lokasi penanaman dan selanjutnya dikirim ke laboratorium dengan dimasukkan pada kotak styrofoam.

\section{Preparasi daun}

Daun G. versteegii dari Bogor, Mataram dan Sambas dibersihkan dari kotoran yang menempel dengan air mengalir dan kemudian dikering-anginkan dalam ruangan sampai kering. Untuk pengeringan selanjutnya, sampel daun dikemas dalam amplop coklat dan dioven pada suhu $40^{\circ} \mathrm{C}$ selama \pm 6 hari atau sampai tercapai berat konstan. Daun kering diblender hingga menjadi serbuk dan diayak untuk menyamakan ukuran serbuk simplisa. Simplisia selanjutnya disimpan pada suhu ruang hingga digunakan pada tahap selanjutnya.

\section{Ekstraksi daun}

Ekstraksi dilakukan dengan metode soxhletasi dengan pelarut metanol p.a. Sebanyak $20 \mathrm{~g}$ simplisia dikemas dalam kertas saring dan diekstrak dengan $150 \mathrm{~mL}$ metanol. Soxhletasi dilakukan pada suhu $75-80^{\circ} \mathrm{C}$ sebanyak 24 siklus atau sampai pelarut berwarna bening. Ekstrak yang diperoleh dikeringkan dan ditimbang untuk dihitung rendemennya. Ekstrak kering disimpan dalam botol vial $5 \mathrm{~mL}$ dan disimpan dalam lemari es sampai percobaan berikutnya.

\section{Fraksinasi ekstrak metanol}

Fraksinasi cair-cair dilakukan dengan dua pelarut yaitu aquades dan kloroform. Sebanyak 3 g ekstrak metanol kering dilarutkan dengan 80 $\mathrm{mL}$ aquades. Setelah larut, larutan ekstrak dipindahkan ke corong pisah dan ditambah 80 $\mathrm{mL}$ kloroform untuk mendapatkan perbandingan 1:1. Corong pisah dibolak-balik secara berkala untuk memastikan fraksinasi berjalan efisien dan selanjutnya campuran diinkubasi selama 24 jam untuk mendapatkan dua lapisan yang terpisah sempurna. Kedua pelarut dituang pada cawan porselen dan dikeringkan dengan rotary evaporator. Fraksi kering disimpan dalam botol vial $5 \mathrm{~mL}$ dan ditimbang untuk penghitungan 
rendemen yang diperoleh. Fraksi selanjutnya disimpan dalam lemari es sampai percobaan selanjutnya.

\section{Kromatografi lapis tipis (KLT)}

Sebanyak $50 \mathrm{mg}$ sampel baik ekstrak atau fraksi dilarutkan dengan $50 \mu \mathrm{L}$ pelarut yang sesuai (tergantung jenis fraksi) di dalam microtube dan dicampur dengan vortex selama \pm 3 menit. Plat silika $\mathrm{GF}_{254}$ dipotong dengan ukuran $4 \times 10 \mathrm{~cm}$, dibuat garis batas atas $0,5 \mathrm{~cm}$ dan batas bawah $1,5 \mathrm{~cm}$ dengan pensil. Sebelum digunakan plat diaktifkan dengan pemanasan dalam oven selama \pm 15 menit pada suhu $70^{\circ} \mathrm{C}$. Penotolan sampel pada plat silika dilakukan dengan haematokrit. Setiap penotolan sampel, segera dikeringkan agar totolan membentuk noda yang kompak. Eluen pengembang KLT yang sesuai dengan fraksi (Tabel 1.), disiapkan dan dimasukkan dalam bejana pengembang yang ditutup selama \pm 45 menit sebelum digunakan. Pada saat yang sama dimasukkan juga kertas saring sepanjang bejana untuk memonitor perambatan pelarut dalam bejana. Tahap ini penting untuk menjenuhkan ruang dalam bejana.

Tabel 1. Kombinasi pelarut pengembang yang digunakan dalam KLT ekstrak/fraksi Gyrinops versteegii

\begin{tabular}{ccc}
\hline $\begin{array}{c}\text { eluen (fase } \\
\text { gerak) }\end{array}$ & Perbandingan & Jenis fraksi \\
\hline $\begin{array}{c}\text { n-heksan: } \\
\text { etil asetat }\end{array}$ & $7: 3$ dan 7:5 & $\begin{array}{c}\text { Non polar (fraksi } \\
\text { kloroform) }\end{array}$ \\
\hline $\begin{array}{c}\text { Metanol: } \\
\text { Aseton: }\end{array}$ & $2: 4: 1$ & $\begin{array}{c}\text { Polar (fraksi } \\
\text { aquades) }\end{array}$ \\
Aquades & & \\
\hline
\end{tabular}

Plat KLT yang sudah ditotol dengan sampel dimasukkan ke dalam bejana yang telah terjenuhi uap pelarut. Pengembangan plat KLT dilakukan sampai rambatan pelarut mencapai garis penanda atas. Plat diangkat dan dikeringkan dengan hair dryer. Plat diamati pada cahaya tampak, di bawah sinar UV $254 \mathrm{~nm}$ dan $366 \mathrm{~nm}$ sebelum disemprot dengan reagen pendeteksi. Reagen pendeteksi yang digunakan adalah vanilin sulfat dan $\mathrm{FeCl}_{3}$. Vanilin sulfat untuk deteksi golongan senyawa terpenoid, sedangkan ferric chloride untuk deteksi golongan senyawa flavonoid dan fenolik. Plat KLT difoto dan dibuat diagram representatif spot yang terbentuk. Spot yang terbentuk dari setiap penyemprotan dihitung nilai Racing factor ( $R f$ ) nya.

\section{Analisis data}

Hasil ekstraksi dan fraksinasi dihitung nilai rendemennya dengan rumus:

rendemen $=\frac{\text { massa ekstrak } / \text { fraksi }}{\text { massa simplisia } / \text { ekstrak }} \times 100 \%$

(Maylani, 2020)

Spot KLT yang terbentuk dihitung nilai $R f$ nya dengan rumus:

$$
R f=\frac{\text { jarak } \text { rambatan } \text { spot }}{\text { jarak } \text { rambatan eluen }}
$$

(Sherma \& Zweig, 2013)

Nilai $R f$ yang terbentuk diolah menjadi data binary dengan mengumpulkan semua nilai $R f$ dan mengevaluasi dengan cara ada spot / tidak ada spot dengan nilai $1 / 0$. Selanjutnya data diolah menggunakan software SIMCA 16 (Sartorius) untuk multivariate data analysis (MVA) yang dilanjutkan dengan Hierarchical Cluster Analysis (HCA). Analisis MVA dilakukan untuk penghitungan principal component (PC) 1 dan 2 dan kedua PC tersebut digunakan untuk HCA dengan metode single linkaged untuk penghitungan jaraknya.

\section{Hasil dan Pembahasan}

\section{Ekstraksi daun}

Hasil ekstraksi daun gaharu dari tiga lokasi menunjukkan hasil ekstrak dengan berat yang bervariasi. Rendemen tertinggi diperolah dari sampel Mataram sebanyak 31,6\% diikuti oleh Bogor dan Sambas dengan nilai rendemen berturut-turut $25,9 \%$ dan 24,05\% (Tabel 2.).

Tabel 2. Hasil ekstraksi metabolit sekunder daun gaharu Gyrinops versteegii dengan metode soxhletasi mengunakan pelarut metanol.

\begin{tabular}{cccc}
\hline \multirow{2}{*}{$\begin{array}{c}\text { Lokasi } \\
\text { tumbuh }\end{array}$} & $\begin{array}{c}\text { Masa } \\
\text { Simplisia } \\
\end{array}$ & \multicolumn{2}{c}{ Pelarut metanol } \\
\cline { 3 - 4 } & $\mathrm{g})$ & $\begin{array}{c}\text { Masa } \\
\text { Ekstrak }(\mathrm{g})\end{array}$ & $\begin{array}{c}\text { Rendemen } \\
(\%)\end{array}$ \\
\hline Bogor & 20 & $5,18 \pm 1,36$ & 25,9 \\
\hline Mataram & 20 & $6,32 \pm 1,52$ & 31,6 \\
\hline Sambas & 20 & $4,81 \pm 1,45$ & 24,05 \\
\hline
\end{tabular}


Hasil tersebut sejalan dengan penelitian Widayat et al., (2021) yang menyatakan bahwa ekstraksi daun $G$. versteegii dari Mataram memberikan hasil lebih banyak dibanding ekstraksi daun gaharu dari Bogor. Hal ini dimungkinan karena perbedaan lingkungan tumbuh dari masing-masing daerah. Diketahui bahwa wilayah Mataram adalah daerah yang memiliki suhu udara yang lebih tinggi dengan suhu rata-rata tahunan berkisar $27^{\circ} \mathrm{C}$, sedangkan wilayah Bogor dan Kalimantan memiliki suhu rata-rata tahunan berkisaran $25{ }^{\circ} \mathrm{C}$ dan $26{ }^{\circ} \mathrm{C}$ (BPS, 2015). Peningkatan suhu dan $\mathrm{CO}_{2}$ pada lingkungan dapat meningkatkan kandungan senyawa Biogenic volatile organic compound (BVOC) serta akumulasi biosintesis senyawa fenolik (Austen et al., 2019). Peningkatan suhu juga dapat meregulasi sintesis isoprena pada tumbuhan untuk mengikat radikal bebas dan Reactive oxygen species (ROS) yang berpotensi menyebabkan stres oksidatif (Wolfertz et al., 2004). Pembentukan isoprena dibentuk melalui jalur sintesis yang lebih rumit, sehingga tumbuhan seringkali menggunakan jalur biosintesis fenolik dan flavonoid sebagai pendaur radikal bebas akibat cekaman (Austen et al., 2019; Wolfertz et al., 2004).

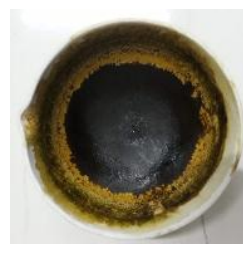

a

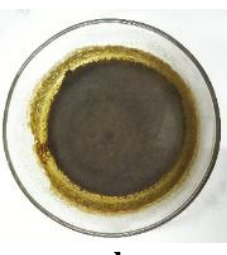

b

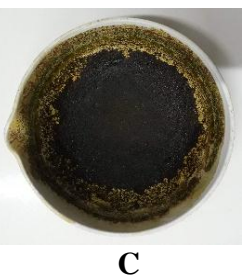

C
Gambar 1. Morfologi ekstrak metanol daun gaharu Gyrinops versteegii. (a) Ekstrak daun asal Bogor; (b) Ekstrak daun asal Mataram; (c) Ekstrak daun asal Sambas.

Karakteristik ekstrak yang diperoleh menunjukkan konsistensi ekstrak yang sedikit berbeda. Ekstrak sampel Mataram dan Sambas memiliki karakter yang kering dan licin sedangkan ekstrak sampel Bogor menyerupai pasta. Menurut Wardana et al., 2019, kondisi kering dan licin pada ekstrak dapat disebabkan adanya kandungan minyak atsiri yang larut dalam pelarut polar, sedangkan morfologi ekstrak pasta dapat disebabkan adanya senyawa golongan sterol. (Gambar 1.). Pelarut metanol dikenal sebagai pelarut universal yang mampu menarik senyawa yang bersifat non-polar dan polar. Sifat metanol merupakan pelarut yang lebih polar dari etanol, akan tetapi gugus hidroksil $(-\mathrm{OH})$ dan gugus metil $\left(-\mathrm{CH}_{3}\right)$ yang letaknya berdekatan menyebabkan pembentukan dua kutub polar dan non polar yang menjadinya pelarut universal yang mampu mengekstrak senyawa yang polar dan non polar (Tiwari et al., 2011; Wardana et al., 2019).

\section{Fraksinasi daun Gyrinops versteegii}

Hasil fraksinasi daun gaharu menunjukkan bahwa sebagian besar ekstrak metanol difraksinasi ke dalam fraksi aquades dengan perbandingan rendemen $60-70 \%$ fraksi aquades dan 6-8\% fraksi kloroform. Hal ini mengindikasikan bahwa metabolit utama penyusun ekstrak metanol daun gaharu $G$. versteegii bersifat polar. Pada fraksi aquades, rendemen terbesar diperoleh dari sampel Mataram sebanyak 76,3\% diikuti dari Bogor dan Sambas berturut-turut $71,3 \%$ dan $64,6 \%$. Sedangkan pelarut kloroform persentase rendemen terbanyak berasal dari sampel Mataram 8\%, Bogor 6,3\% dan Sambas $6 \%$ (Tabel 3.).

Tabel 3. Hasil fraksinasi cair-cair ekstrak metanol daun G. versteegii

\begin{tabular}{ccccc}
\hline \multirow{5}{*}{ Pelarut } & & \multicolumn{3}{c}{ karakter fraksi } \\
\cline { 3 - 5 } & $\begin{array}{c}\text { Lokasi } \\
\text { tumbuh }\end{array}$ & $\begin{array}{c}\text { Masa } \\
\text { ekstrak } \\
(\mathrm{g})\end{array}$ & $\begin{array}{c}\text { Hasil } \\
\text { fraksi }\end{array}$ & $\begin{array}{c}\text { Rendemen } \\
(\%)\end{array}$ \\
\hline \multirow{3}{*}{ Kloroform } & Bogor & 3 & 0,19 & 6,3 \\
& Mataram & 3 & 0,24 & 8 \\
& Sambas & 3 & 0,18 & 6 \\
\hline \multirow{3}{*}{ Aquades } & Bogor & 3 & 2,14 & 71,3 \\
& Mataram & 3 & 2,29 & 76,3 \\
& Sambas & 3 & 1,94 & 64,6 \\
\hline
\end{tabular}

Faktor lain yang dapat mempengaruhi persentase rendemen ekstrak selain pelarut adalah kondisi lingkungan seperti unsur hara dan curah hujan. Berdasarkan data BPS (2019) ratarata curah hujan Mataram berkisar 144 $\mathrm{mm} /$ tahun, Sambas $162 \mathrm{~mm} /$ tahun dan Bogor $198 \mathrm{~mm} /$ tahun. Berdasarkan data tersebut, Mataram adalah daerah kering dengan curah hujan yang rendah. Rendahnya air tanah dilaporkan mampu meningkatkan aktivitas enzim Phenylalanine Ammonia-lyase (PAL). Enzim tersebut merupakan enzim kunci dalam sintesis senyawa fenolik dan flavonoid (Sampaio et al., 2016). Oleh karena itu, tanaman yang 
tumbuh di daerah yang kering cenderung memproduksi metabolit sekunder, termasuk fenolik dan flavonoid yang lebih banyak dari tanaman sejenis yang tumbuh di daerah subur. Hal ini mungkin yang terjadi pada sampel Mataram sehingga memberikan rendemen yang lebih tinggi dari sampel lokasi tumbuh lain.

Keberadaan mineral penting seperti kalium juga mampu mempengaruhi sintesis metabolit sekunder. Menurut Noorita (2020) dan Widayat et al. (2021), kandungan kalium total tanah di lokasi tumbuh kota Sambas hanya 0,16 $\%$ dan Mataram 0,19\%. Kondisi tersebut lebih rendah jika dibandingkan kadar kalium total tanah dari Bogor sebanyak 0,44\%. Rendahnya kalium pada unsur hara dapat menurunkan aktivitas fotosintesis sehingga translokasi karbohidrat dan beberapa jenis metabolit sekunder turunan metabolisme karbohidrat akan mengalami penghambatan (Ibrahim et al., 2012). $\mathrm{Hal}$ ini kemungkinan menjadi penyebab rendahnya fraksi yang dihasilkan sampel Sambas.

\section{Profil metabolit fraksi daun Gyrinops versteegii}

Hasil uji KLT dari ketiga lokasi tumbuh memperlihatkan hasil bahwa fraksi kloroform $G$. versteegii mengandung terpenoid, flavonoid dan fenolik (Gambar 2.). Pada pengembangan KLT dengan campuran pelarut $n$-heksan dan etil asetat rasio 7:3, bercak positif terbanyak diperlihatkan oleh fraksi Bogor yaitu 12 bercak, disusul Mataram dengan 9 bercak dan 8 bercak pada sampel asal Sambas (Tabel 4.). Hasil yang berbeda ditunjukkan pada fraksi aquades $G$. versteegii. Hasil identifikasi untuk golongan senyawa terpenoid, flavonoid dan fenolik dilakukan dengan pengembangan plat KLT dengan campuran pelarut metanol, aseton, dan aquadesdengan perbandingan 2:4:1. Hasil KLT menunjukkan 6 bercak positif pada sampel Mataram, 5 pada sampel Bogor dan 4 pada sampel Sambas (Gambar 3.; Tabel 5.).

Hasil KLT tersebut menunjukkan bahwa sampel Bogor terdeteksi lebih banyak bercak positif dibandingkan sampel Mataram dan Sambas. Perbedaan kandungan metabolit sekunder pada tanaman satu spesies yang ditanam pada lokasi yang berbeda, mengindikasikan pengaruh lokasi tumbuh terhadap metabolisme sekunder (Sampaio et al., 2016). Hasil ini berbeda dengan hasil pada rendemen (Tabel 3.), yang menunjukkan persentase tertinggi dari sampel Mataram, disusul Bogor dan terakhir Sambas.

Tabel 4. Racing Factor (Rf) bercak hasil KLT fraksi kloroform dari ekstrak metanol daun Gyrinops versteegii

\begin{tabular}{|c|c|c|c|}
\hline \multirow{2}{*}{$\begin{array}{c}\text { Golongan } \\
\text { senyawa }\end{array}$} & \multicolumn{3}{|c|}{ Racing Factor } \\
\hline & Bogor & Mataram & Sambas \\
\hline \multirow[t]{5}{*}{ Terpenoid } & 0,28 & 0,28 & 0,28 \\
\hline & 0,53 & 0,47 & 0,53 \\
\hline & 0,61 & 0,58 & 0,75 \\
\hline & 0,70 & 0,61 & - \\
\hline & 0,75 & - & - \\
\hline \multirow[t]{4}{*}{ Fenolik } & 0,47 & 0,47 & 0,47 \\
\hline & 0,61 & 0,61 & 0,61 \\
\hline & 0,71 & - & - \\
\hline & 0,80 & - & - \\
\hline \multirow[t]{3}{*}{ Flavonoid } & 0,25 & 0,25 & 0,25 \\
\hline & 0,43 & 0,43 & 0,56 \\
\hline & 0,50 & 0,97 & - \\
\hline
\end{tabular}

Tabel 5. Racing Factor (Rf) bercak hasil KLT fraksi aquades dari ekstrak metanol daun Gyrinops versteegii

\begin{tabular}{cccc}
\hline \multirow{2}{*}{ Golongan } & \multicolumn{3}{c}{ Racing Factor } \\
\cline { 2 - 4 } Senyawa & Bogor & Mataram & Sambas \\
\hline Terpenoid & 0,37 & 0,66 & 0,62 \\
& 0,62 & 0,77 & - \\
\hline Fenolik & 0,47 & 0,67 & 0,55 \\
& 0,67 & 0,80 & 0,67 \\
\hline Flavonoid & 0,73 & 0,81 & 0,81 \\
& 0,81 & - & - \\
\hline
\end{tabular}

Keberagaman jenis metabolit sekunder sangat dipengaruhi oleh cekaman biotik yang diterima oleh tanaman. Metabolit sekunder merupakan metabolit yang disintesis untuk pertahanan tumbuhan menghadapi serangan hama dan penyakit (Ashraf et al., 2018). Tingginya keberagaman bercak pada sampel Bogor mungkin dipengaruhi oleh kondisi lokasi tumbuhnya seperti yang disampaikan oleh Widayat et al. (2021). Tanaman G. versteegii di Kebun Raya Bogor ditanam bersama-sama dengan tanaman jenis lain, sedangkan di Mataram dan Sambas ditanam berkelompok dalam perkebunan monokultur. Kondisi di Kebun Raya Bogor menyebabkan tanaman mempunyai kemungkinan berinteraksi lebih banyak dengan beragam jenis polyphagous herbivore, sehingga memicu sintesis beragam jenis metabolit 
sekunder (Singh et al., 2021). Kondisi penanaman monokultur juga mengurangi kompetisi sumber makanan dengan tanaman jenis lain sehingga besar kemungkinan tanaman G. versteegii tidak terpicu menghasilkan allelopati (Kraus et al., 2002).

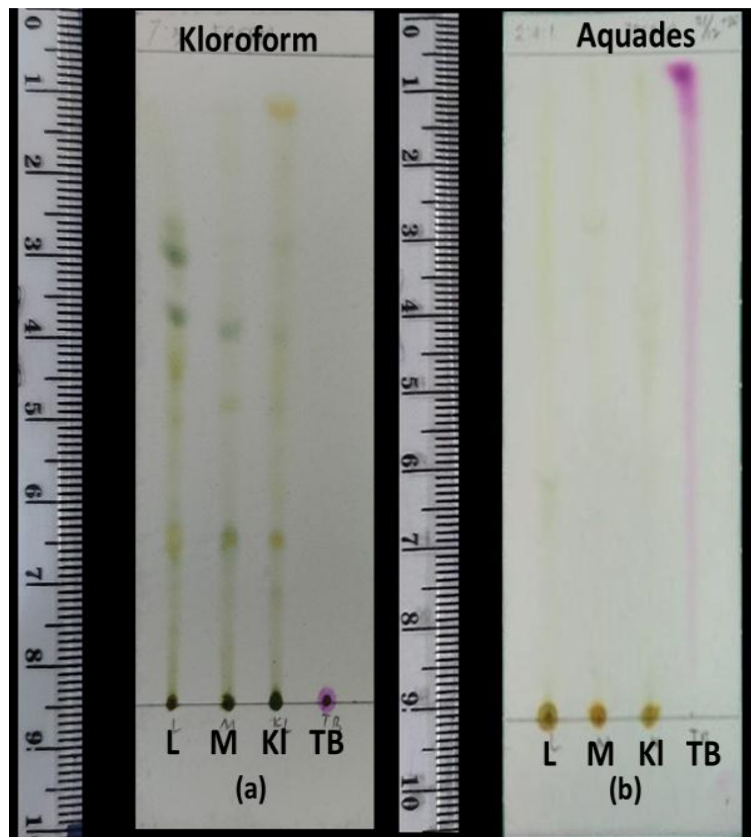

Gambar 2. Representatif hasil kromatografi lapis tipis (a) fraksi kloroform, 7:3 (n-heksan : etil-asetat) (b) fraksi aquades 2:4:1 (Metanol: Aseton: Aquades) Gyrinops versteegii Bogor (L), Mataram (M), dan Sambas (K), Timol biru (TB) yang disemprot dengan pereaksi vanilin sulfat.

Hasil KLT fraksi kloroform menunjukkan kandungan metabolit sekunder yang lebih banyak dan beragam dibanding fraksi aquades. Perbedaan jumlah bercak yang terdeteksi pada fraksi kloroform dan fraksi aquades disebabkan karena perbedaan karakter pelarutnya (Cai, 2014) (Gambar 2.). Fraksi aquades mengandung metabolit sekunder yang bersifat polar seperti antosianin, karena pengaruh dari polaritas aquadesyang sangat tinggi (Das et al., 2010). Selain antosianin, aquades juga mampu mengekstrak metabolit sekunder lain seperti alkaloid, saponin dan tanin. Sedangkan kloroform dapat mengekstrak jenis steroid, terpenoid, dan flavonoid (Das et al., 2010; Tiwari et al., 2011) (Gambar 3.; Gambar 4.).

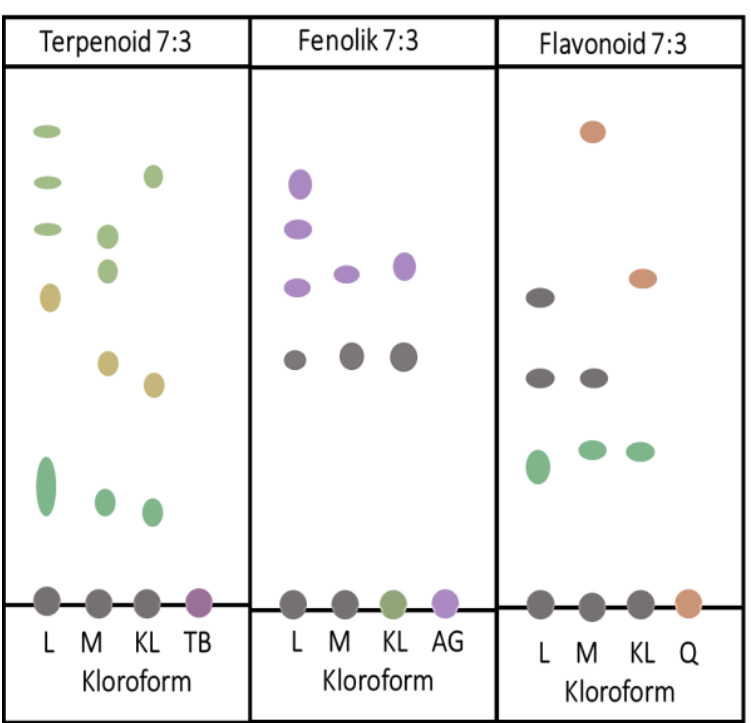

Gambar 3. Diagram representatif hasil KLT pada deteksi golongan senyawa terpenoid, fenolik, dan flavonoid fraksi kloroform, 7:3 (n-heksan : e-asetat) Gyrinops versteegii Bogor (L), Mataram (M), dan Sambas (KL), Timol blue (TB), Asam Galat (AG), dan Quercetin (Q).

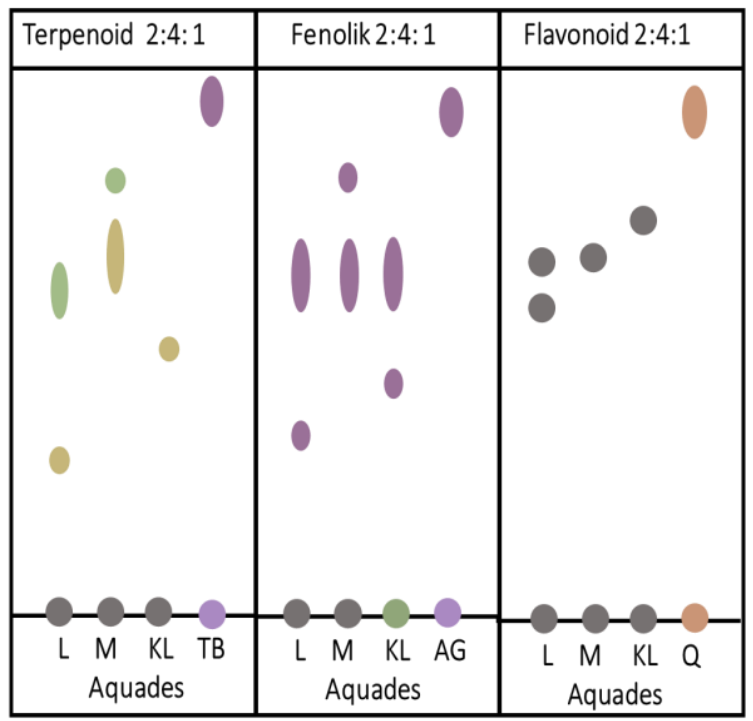

Gambar 4. Diagram representatif hasil KLT pada deteksi golongan senyawa terpenoid, fenolik, dan flavonoid fraksi aquades, 2:4:1 (Metanol: Aseton: Aquades) Gyrinops versteegii Bogor (L) , Mataram (M), dan Sambas (KL), Timol blue (TB), Asam Galat (AG), dan Quersetin (Q).

Nilai $R f$ bersifat spesifik untuk suatu senyawa tertentu, karena jarak rambatan suatu senyawa dalam KLT dipengaruhi oleh kemampuan senyawa tersebut terlarut dan ikut bermigrasi dengan fase geraknya sekaligus interaksinya dengan plat silika sebagai fase 
diamnya (Sastrohamidjojo, 2002). Pada fraksi kloroform terdeteksi satu bercak terpenoid yang terdapat pada semua lokasi dengan nilai $R f 0,28$. Bercak positif fenolik mempunyai dua bercak yang terdapat di sampel ketiga lokasi yaitu $R f$ 0,47 dan 0,6 sedangkan untuk flavonoid hanya terdeteksi satu bercak dengan $R f$ 0,25 yang terdeteksi di ketiga sampel. Fraksi aquades memiliki lebih sedikit bercak yang ditemukan pada tiga lokasi sampel. Hanya golongan fenolik pada $R f 0,67$ dan flavonoid pada $R f 0,81$ yang ditemukan pada tiga lokasi serta tidak ditemukan bercak dengan $R f$ yang sama pada golongan terpenoid.

Data $R f$ dari hasil KLT pada Tabel 4 dan 5. selanjutnya diolah dengan HCA sehingga diperoleh dendogram seperti pada Gambar 5. Hasil HCA diperoleh dua kelompok besar, dimana sampel Mataram terpisah dari sampel Bogor dan Sambas. Perbedaan sampel Mataram dari sampel lain besar kemungkinan karena hasil deteksi KLT fraksi kloroform untuk golongan terpenoid menunjukkan jumlah kesamaan yang lebih banyak pada nilai $R f$ sampel Bogor dengan sampel Sambas yaitu pada $R f 0,28 ; 0,53$ dan 0,75 dibandingkan sampel Mataram. Fraksi aquades juga menunjukkan satu bercak untuk golongan terpenoid dengan nilai $R f$ sama pada sampel Bogor dan Sambas. Hal ini tidak terdeteksi pada sampel Mataram.

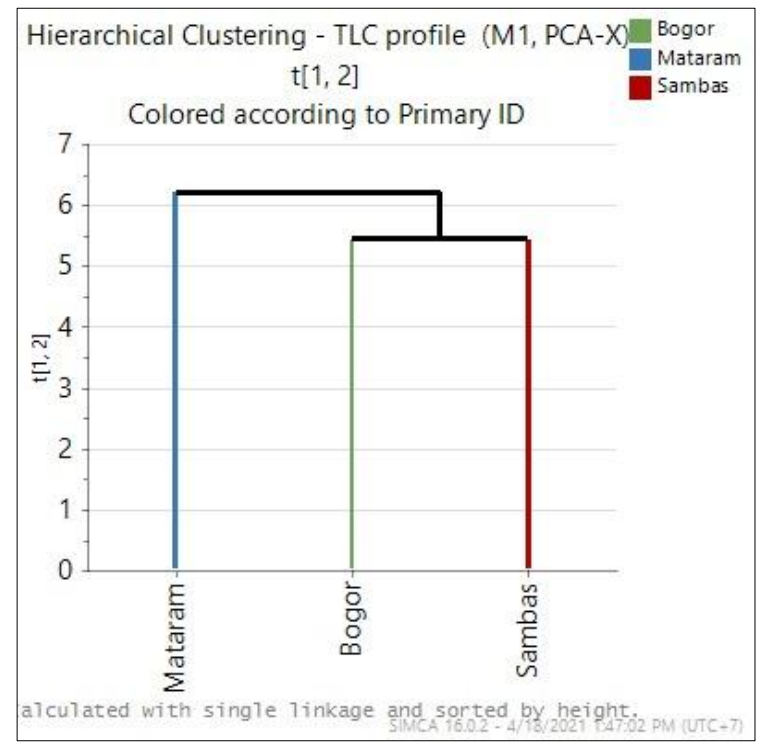

Gambar 5. Dendrogram hasil hierarchical cluster analysis (HCA) dari hasil KLT fraksi kloroform dan fraksi aquades Gyrinops versteegii asal tiga lokasi tumbuh: Bogor, Mataram, dan Sambas.

\section{Kesimpulan}

Berdasarkan hasil penelitian dapat disimpulkan bahwa terdapat variasi kandungan profil metabolit daun $G$. versteegii yang tumbuh di tiga wilayah berbeda Bogor, Mataram dan sambas. Wilayah Mataram memberikan hasil ekstrak dan fraksi tertinggi dibanding wilayah lain, dengan nilai sebesar 31,6\% pada ekstrak metanol, $8 \%$ pada fraksi kloroform dan 76,3\% pada fraksi aquades. Hasil kromatografi lapis tipis KLT Fraksi kloroform memiliki kandungan golongan senyawa terpenoid, fenolik dan flavonoid yang lebih beragam dibandingkan fraksi aquades. Hasil variasi golongan senyawa pada KLT tersebut selanjutnya dianalisis menggunakan HCA menunjukkan bahwa, terdapat dua kelompok besar, dimana sampel Mataram terpisah dari sampel Bogor dan Sambas.

\section{Ucapan terima kasih}

Terima Kasih kepada Direktorat Riset dan Pengabdian Masyarakat Kemenristek-Dikti atas dukungan pendanaan melalui skema PDUPT No. 2726/UN1.DITLIT/DIT-LIT/PT/2020.

\section{Referensi}

Abdullahi R., Abubakar, \& Hague, M. (2017). Methodology Used in the Study. Asian Journal of Pharmaceutical and Clinical Research, $\quad 7(10), \quad 1-5$. https://doi.org/10.4103/jpbs.JPBS

Ashraf, M. A., Iqbal, M., Rasheed, R., Hussain, I., Riaz, M., \& Arif, M. S. (2018). Environmental Stress and Secondary Metabolites in Plants: An Overview. In Plant Metabolites and Regulation under Environmental Stress (Issue June 2019). https://doi.org/10.1016/B978-0-12812689-9.00008-X

Austen, N., Walker, H. J., Lake, J. A., Phoenix, G. K., \& Cameron, D. D. (2019). The Regulation of Plant Secondary Metabolism in Response to Abiotic Stress: Interactions Between Heat Shock and Elevated CO2. Frontiers in Plant Science, 10(November), 1-12. 
https://doi.org/10.3389/fpls.2019.01463

BPS (2021). Rata-Rata Suhu Udara, Kelembaban, Tekanan Udara, Kecepatan Angin, Curah Hujan, dan Penyinaran Matahari. Menurut Stasiun Cuaca di Indonesia $2016 \quad$ - 2019. https://www.bps.go.id/statictable/2019/02 /08/1959/jumlah-curah-hujan-danjumlah-hari-hujan-di-stasiunpengamatan-bmkg-2011-2015.html. Accessed on Thursday, april 8 th 2021 at 23:01 WIB (2021).

BPS (2021). Letak Geografis, Titik Kordinat Garis Lintang. Menurut Stasiun Geografis Indonesia 2015. https://kaltim.bps.go.id/statictable/2015/0 3/03/2/letak-batas-dan-luas-provinsikabupaten html. Accessed on Thursday, april 8 th 2021 at 23:01 WIB (2021).

Cai, L. (2014). Thin layer chromatography. Current Protocols in Essential Laboratory Techniques, 2014(February 2014), 6.3.16.3.18.

https://doi.org/10.1002/9780470089941.et 0603s08

Das, K., Tiwari, R. K. S., \& Shrivastava, D. K. (2010). Techniques for evaluation of medicinal plant products as antimicrobial agent: Current methods and future trends. Journal of Medicinal Plants Research, 4(2), 104-111. https://doi.org/10.5897/JMPR09.030

Ibrahim, M. H., Jaafar, H. Z. E., Karimi, E., \& Ghasemzadeh, A. (2012). Primary, secondary metabolites, photosynthetic capacity and antioxidant activity of the Malaysian Herb Kacip Fatimah (Labisia pumila Benth) exposed to potassium fertilization under greenhouse conditions. International Journal of Molecular Sciences, 13(11), 15321-15342. https://doi.org/10.3390/ijms131115321

Kraus, E., Voeten, M., \& Lambers, H. (2002). Allelopathic and autotoxic interactions in selected populations of Lolium perenne grown in monoculture and mixed culture.
Functional Plant Biology, 29(12), 14651473. https://doi.org/10.1071/FP02063.

LIPI (2015) - Indonesia. Indonesia Miliki 7.500 Tanaman

Obat. http://lipi.go.id/berita/single/IndonesiaMiliki-7500-Tanaman-Obat/11540.

Diakses tanggal 18 Desember 2019.

Maylani Haniva. (2020). STANDARDISASI SEDIAAN EKSTRAK DAUN GAHARU Aquilaria malaccensis Lamk. DARI LOKASI TUMBUH BERBEDA DI INDONESIA. Skripsi.

Mulyaningsih, T., Marsono, D., \& Yamada, I. (2014). Selection of Superior Breeding Infraspecies Gaharu of. 4(January), 485492.

Norita, A. (2020). Standarisasi Sediaan Ekstrak Daun Gaharu (Gyrinops versteegii (Gilg.) Domke) dari Tiga Lokasi Berbeda di Indonesia. Skripsi.

Novriyanti, E., Santosa, E., Syafii, W., Turjaman, M., \& Sitepu, I. R. (2010). Anti Fungal Activity of Wood Extract of Aquilaria crassna Pierre ex Lecomte Against Agarwood-Inducing Fungi, Fusarium solani. Indonesian Journal of Forestry Research, 7(2), 155-165. https://doi.org/10.20886/ijfr.2010.7.2.155 $-165$

Nuringtyas, T. R., Isromarina, R., Septia, Y., Hidayati, L., Wijayanti, N., \& Moeljopawiro, S. (2018). The antioxidant and cytotoxic activities of the chloroform extract of agarwood (Gyrinops versteegii (Gilg.) Domke) leaves on HeLa cell lines. AIP Conference Proceedings, 2002(2018). https://doi.org/10.1063/1.5050163

Ramakrishna, A., \& Ravishankar, G. A. (2011). Influence of abiotic stress signals on secondary metabolites in plants. Plant Signaling and Behavior, 6(11), 17201731. https://doi.org/10.4161/psb.6.11.17613

Rindyastuti, R., Yulistyarini, T., \& Darmayanti, A. S. (2019). Population and ecological 
study of agarwood producing tree (Gyrinops versteegii) in Manggarai district, Flores island, Indonesia. Biodiversitas, 20(4), 1180-1191. https://doi.org/10.13057/biodiv/d200434

Sampaio, B. L., Edrada-ebel, R., Batista, F., \& Costa, D. (2016). Effect of the environment on the secondary metabolic profile of Tithonia diversifolia : a model for environmental metabolomics of plants. Nature Publishing Group, July, 1-11. https://doi.org/10.1038/srep29265

Sastrohamidjojo,H., 2002, Kromatografi, Edisi Kedua, 26-32, Penerbit Liberty Yogyakarta, Yogyakarta.Singh, S., Kaur, I., \& Kariyat, R. (2021). The multifunctional roles of polyphenols in plant-herbivore interactions. International Journal of Molecular Sciences, 22(3), 119. https://doi.org/10.3390/ijms22031442

Sumarni, W., Sudarmin, S., \& Sumarti, S. S. (2019). The scientification of jamu: A study of Indonesian's traditional medicine. Journal of Physics: Conference Series, 1321(3). https://doi.org/10.1088/17426596/1321/3/032057

Susilo, A. (2014). Panduan Lapangan Pengenalan Jenis Pohon Penghasil Gaharu Gyrinops spp . di Indonesia.

Tiwari, P., Kumar, B., Kaur, M., Kaur, G., \& Kaur, H. (2011). Phytochemical screening and Extraction: A Review. Internationale Pharmaceutica Sciencia| Jan-March 2011 | Vol. 1 | Issue 1, 1(1). https://doi.org/10.1002/hep.29375

Wahyuni, R., Prihantini, A. I., \& Anggadhania, L. (2020). Formation of Gyrinops versteegii Agarwood by Fusarium solani Bioinduction with Simpori Technique. Jurnal Ilmu Pertanian Indonesia, 25(1), 152-159.

https://doi.org/10.18343/jipi.25.1.152

Wardana, T. A. P., Nuringtyas, T. R., Wijayanti, N., \& Hidayati, L. (2019). Phytochemical analysis of agarwood (Gyrinops versteegii
(Gilg.) Domke) leaves extracts as anticancer using GC-MS. AIP Conference Proceedings, 2194(December). https://doi.org/10.1063/1.5139868

Widayat. (2019). Pengaruh perbedaan Lokasi tumbuh TERHADAP PROFIL METABOLIT DAUN GAHARU Gyrinops versteegii ( Gilg .) Domke. Skripsi.

Widayat, T., Hidayati, L., Wijayanti, N., \& Nuringtyas, T. R. (2021). Metabolite Profiles of Agarwood Gyrinops versteegii ( Gilg ) Domke Leaves collected from Different Locations. 16(4), 12-19.

Wolfertz, M., Sharkey, T. D., Boland, W., \& Kühnemann, F. (2004). Rapid regulation of the methylerythritol 4-phosphate pathway during isoprene synthesis. Plant Physiology, 135(4), 1939-1945. https://doi.org/10.1104/pp.104.043737 